\title{
IUGS Proposes Contribution to Global Change
}

The International Geosphere-Biosphere Programme (IGBP) on Global Change will be on those areas involved with key interactions and significant global changes on time scales of decades to centuries. This is understandable in terms of the history of the Earth, for anthropogenically induced changes are taking place at abnormal rates in earth history and represent catastrophic events in geological terms. We have to go far back into the geological record to find examples of interactive physical, chemical, and biological processes that produced changes on the scale of decades to centuries.

To explore the possible contribution by earth scientists to the IGBP, the IUGS Executive Committee set up last year a Task Group on Global Change, chaired by Kenneth J. Hsü (Switzerland). The Task Group proposed that a meeting be held to review the present knowledge of natural and anthropogenic global changes, to identify gaps in present knowledge of global change where geoscientists could make a contribution, to recommend research programs to fill these gaps, and to establish a communication network to implement some of the recommendations.

Accordingly, a "Workshop on Past Global Changes," sponsored by IUGS, Unesco, and the Swiss Academy of Natural Sciences, brought together at Interlaken, Switzerland, in late April 1989 some 70 leading geoscientists. In the manner of the Dahlem conferences, four working groups had been established and had prepared position papers, which were distributed to all participants before the meeting, so that the time in Interlaken could best be used for interdisciplinary discussion and for preparing final reports.

For the Ocean Record of Past Global Changes, the report of WG 1 , chaired by N. Shackleton, (U.K.), indicates that studies of the ocean-atmosphere system at different modes of operation in the past will help to identify where the manmade changes of the system are heading, including nonIinear response beyond certain threshold values. It is, of course, recognized that the paleooceanographic scientific community has been studying Global Change for some time now, and $W G l$ believes that it is essential to get worldwide participation and coverage in the study of the oceanic record. The focus should be on specific time slices in order to maximize the available information for any one time.

WG l proposed three time scales and identified key problems on which the research should concentrate. On the long time scale (last 2-3 glacial cycles), major problems include the extent and dynamies of the ice cover (to be studied in the Arctic Ocean, in high northern latitudes of the Atlantic and Pacific and in the southern ocean), the formation of deep and intermediate water masses, the past record of atmospheric circulation (by studying aeolian deposits in the ocean) and the special regional conditions monitored in marginal basins. The intermediate time scale $\left(10^{3}\right.$ to $10^{4}$ years) aims at non-periodic events like the Younger Dryas or the "little ice ages." On the short time scale of decades to centuries, the human impact on the global environment will be under scrutiny.

Annually laminated sediments and corals of fer high resolution records, as do other rapidly depositing sequences. An important aspect is the correlation of oceanic and continental records. It is proposed to launch a pilot project jointly with WG 2 to test the correlation in an area that has already been extensively studied (NW Europe).
Working Group 2 (Land Record of Past Global Changes, chaired by $N$. Rutter, Canada) will concentrate on an examination of the records of the last glacial cycle, of the Holocene and of the immediate past, when mankind started affecting the global environment. The position papers include an assessment of the terrestrial record of the last glacial cycle, a review of Quaternary palynology, and papers on Quaternary sea-level changes and on paleoenvironmental modelling. The difficult but important task of integrating individual terrestrial records dispersed over all continents was emphasized.

As a means of synthesizing data into a global framework the construction of global paleoenvironmental maps was endorsed. The first goal of this project is to document the state of the continental system at specific critical points of time in the past, and the second objective is to assess the dynamics of the system by studying the changes between subsequent time slices. It was proposed to start with a pilot project of mapping on a global scale the past storage of carbon on the continents at different times, thereby adding to the data base needed for geochemical modelling.

The identification of past and present sea-level changes was another major topic. One need is for a worldwide effort to collect regional data, both from the geological record and from tide gauges, to compile them on a global scale and to make them available to modellers. The second aspect is to decipher from this data set current and future trends in sea-level change and to assess the impact on coastal regions. Programs of this kind do already exist in some countries, but a worldwide coverage is clearly needed.

As regards Anthropogenically Induced Global Change, WG 3, chaired by I. Thornton (U.K.), illustrates the role man plays in changing the global environment with an illustration of the flux rate of material and energy: The $50 \times 10^{9}$ tons of minerals mined annually, for example, exceed by a factor of three the $16.5 \times 10^{9}$ tons of sediment transported to the sea by the rivers of the world. For certain metals the anthropogenic flux is even larger when compared with the

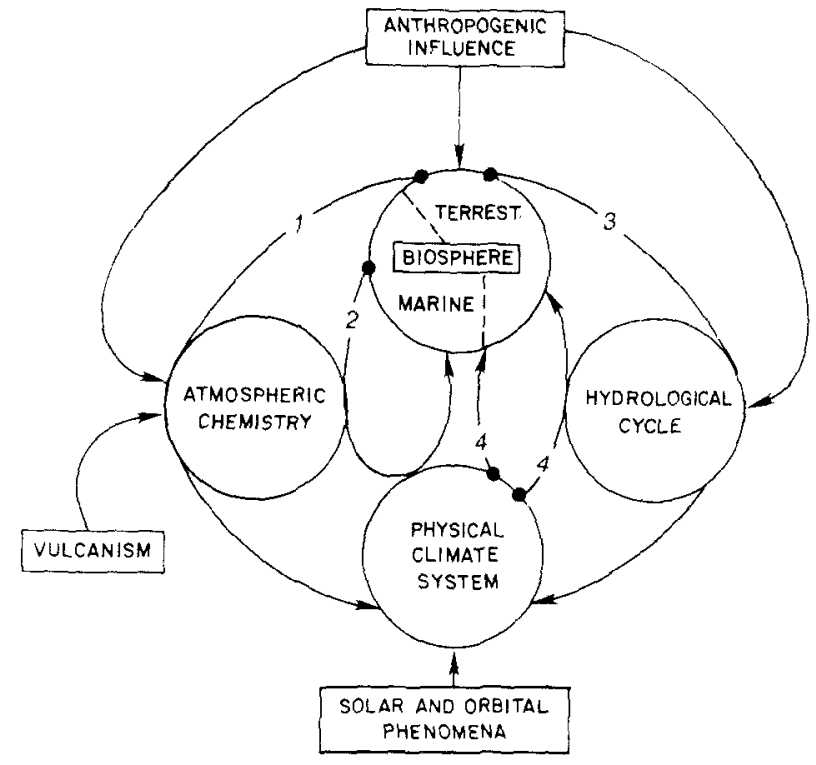


natural flux. The time scale under consideration by WG 3 seldom went beyond the past 2000 years, and the emphasis was placed on the past decades and centuries.

The discussion was centered on two effects of anthropogenic interaction with the environment: the depletion of available resources (soil, groundwater, coastal zones) and the perturbation of global geochemical cycles by industrial, mining and urban activities. There are still large gaps in our knowledge of the present state of pollution and resource depletion and even larger ones concerning the development during the past decades and centuries. But the acquisition of data on the present and the past is essential for determining rates of change and hence for projections into the future. Further topics of discussion were the rehabilitation of contaminated environments, the influence of the geochemical environment on plant, animal and human health, and anthropogenic influences on microbiota.

The nature of past extinctions and the present man-induced extinction event, the similarities and differences between them, and the insights that can be gained from the past were considered by $W G 4$ on the Interaction of Biodiversity Reduction and Global Environment, chaired by D.J. McLaren (U.K.). The most severe direct anthropogenic influences on the biosphere are fragmentation and destruction of natural habitats and the selective elimination of species. Indirectly, man affects ecosystems by causing climatic and geochemical global changes. An alarming feature common to past mass extinctions is that it takes the biological and ecological systems a very long time (millions of years) to recover to pre-event levels of diversity and complexity.

We need to learn a lot more about the patterns of extinction and recovery. Which types of species are extinction-prone and why? Which species are more stress-resistant during past events and during the current crisis? Studying the responses to environmental stress factors of selected modern taxa from victim and survivor lineages of, say, the
$\mathrm{K} / \mathrm{T}$ extinction event will add to our understanding of extinctions. Environmental changes at times of biotic crises need to be investigated, and it is essential to learn more about the mechanisms of recovery after extinction events.

The Interlaken meeting was a great opportunity to share knowledge, viewpoints and ideas and to merge them into a common report, which will be published as a special issue of the journal Global and Planetary Change. More important is the feeling that this was the beginning, not the end, of an effort by earth scientists to contribute to the Global Change program. Annual conferences bringing together scientific leaders will lead to fruitful assessment of progress, but substantial contributions can, however, only be made by involving thousands of earth scientists working on global change problems.

What is needed also is a communication network such as IUGS and Unesco have provided for earth scientists in the IGCP. With dozens of projects working on regional aspects of global changes, a grass-root participation by earth scientists, especially those from developing countries, can be assured. We should explore the possibility of establishing a long-term program of field conferences that would encourage international and interdisciplinary scientific cooperation of scientists, and to facilitate exchanges of ideas, information, samples and personnel. Accordingly the Task Group on Global Change will explore with Unesco a possible cooperative program on Global Change and Earth Sciences as IUGS's contribution to the IGBP.

Acknowledgement: The Interlaken workshop was financially supported by the IUGS, the Intergovernmental Oceanographic Commission and Division of Marine Sciences of Unesco, the Swiss Academy of Natural Sciences, the Swiss National Science Foundation, and the ETH Zürich.

K. J. Hsü and U. Henken-Mellis Zürich, Switzerland

\title{
Geology Today
}

\author{
Published under the co-sponsorship of The Geological Society and \\ The Geologists' Association by Blackwell Scientific Publications Ltd \\ Editors: J.H. McD. Whitaker 11 Guildford Road, Leicester, England and \\ Peter J. Smith 32 St James Close, Hanslope, Milton Keynes, England
}

Geology Today is a magazine for both amateur and professional geologists. The only English-language journal of its kind, Geology Today is designed to provide a wide audience of both specialists and non-specialists with intelligible and readable information from different areas of specialization within both pure and applied geology. The editors select two or three feature articles each issue on various topics of current geological interest. Shorter articles, notes, news of geological meetings, exhibitions and field excursions, contributions from foreign correspondents, as well as book reviews keep both professional and amateur geologists abreast of developments and advances in the field.

\section{Subscription Information}

Geology Today is published bi-monthly. Subscription rates for 1989 are. for individuals $£ 17.50$ (UK). $£ 20.50$ (overseas), $\$ 36.50$ (USA \& Canada). and for institutions $£ 52.50$ (UK). $£ 63 .(0)$ (overseas). $\$ 105.50$ (USA \& Canada) post free. Members of The Geological Society and The Geologists' Association are entitled to subscribe at special rates; details are available from the Society and the Association. All orders and enquiries for sample copies should be sent to the publishers at the address below.

\section{Blackwell Scientific Publications P.O. Box 88, Oxford, England}

